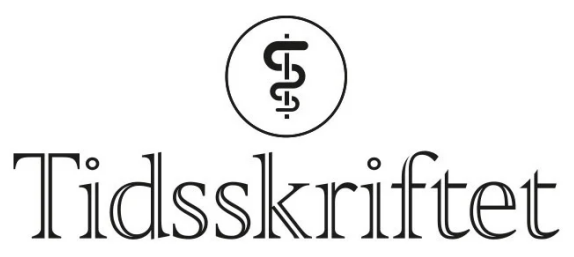

DEN NORSKE LEGEFORENING

\title{
Respiratorbehandling ved amyotrofisk lateral sklerose
}

KRONIKK

\section{OLE-BJØRN TYSNES}

obty@haukeland.no

Ole-Bjørn Tysnes er spesialist i nevrologi, overlege ved Nevrologisk avdeling, Haukeland universitetssjukehus og professor II ved Universitetet i Bergen.

Forfatteren har fylt ut ICMJE-skjemaet og oppgir ingen interessekonflikter.

\section{TRYGVE HOLMØY}

Trygve Holmøy er spesialist i nevrologi, seksjonsoverlege ved Akershus universitetssykehus og professor II ved Universitetet i Oslo.

Forfatteren har fylt ut ICMJE-skjemaet og oppgir ingen interessekonflikter.

\section{SOLFRID INDREKVAM}

Solfrid Indrekvam er spesialist i lungesykdommer og overlege ved Lungeavdelingen, Haukeland universitetssjukehus og leder for Nasjonalt register for langtids mekanisk ventilasjon.

Forfatteren har fylt ut ICMJE-skjemaet og oppgir ingen interessekonflikter.

\section{OVE FONDENAES}

Ove Fondenæs er spesialist i lungesykdommer og overlege ved Lungeavdelingen, Haukeland universitetssjukehus.

Forfatteren har fylt ut ICMJE-skjemaet og oppgir ingen interessekonflikter.

Livsforlengende behandling med ventilasjonsstøtte via trakeostomi benyttes av i underkant av $10 \%$ av pasientene med amyotrofisk lateral sklerose. Det finnes ingen internasjonal konsensus for planlegging av livsforlengende invasiv respiratorbehandling ved denne sykdommen. 


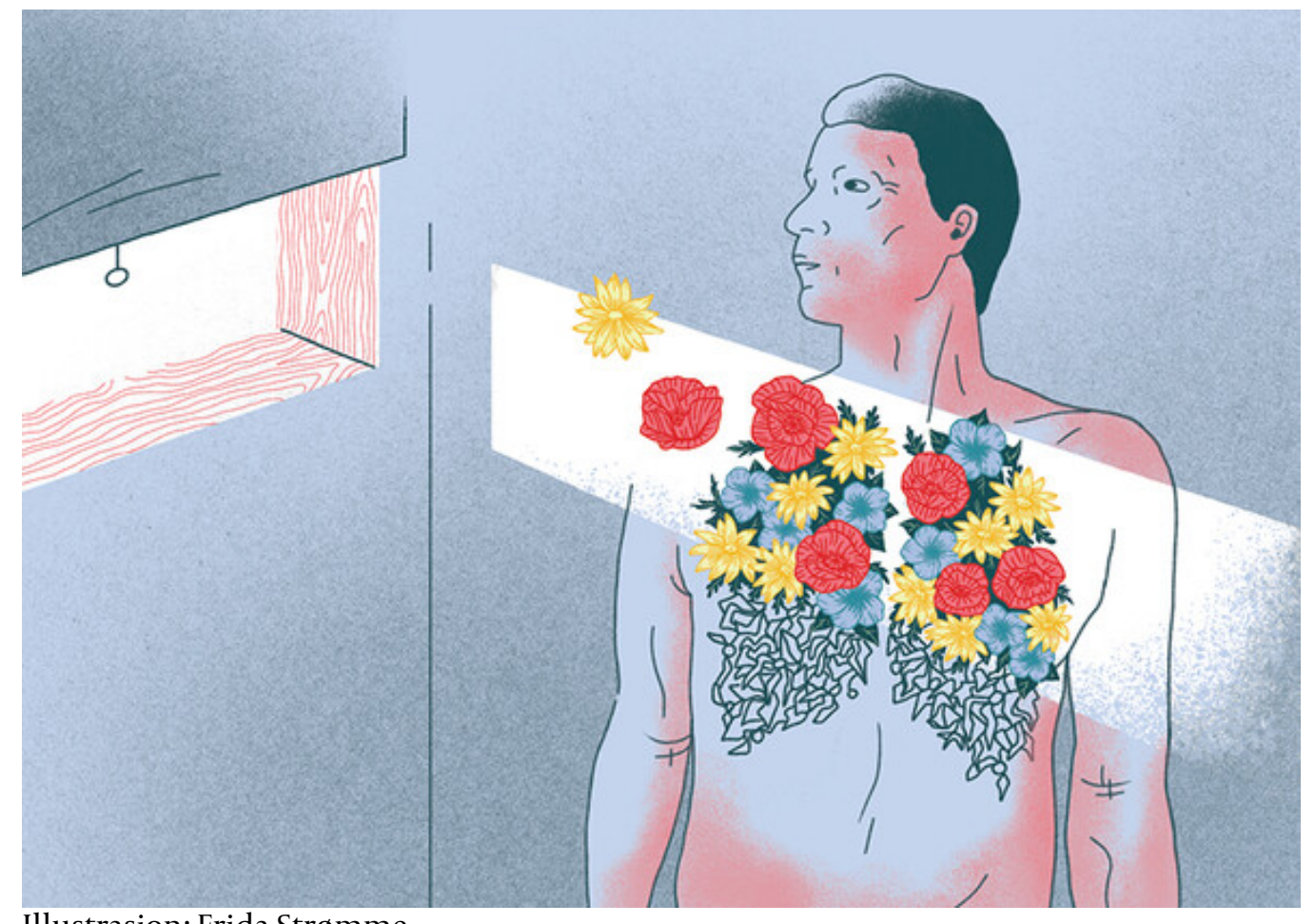

Illustrasjon: Frida Strømme

Amyotrofisk lateral sklerose (ALS) har en årlig insidens i Norge på ca. 3 per 100 ooo, og er litt hyppigere blant menn $(\underline{1}, \underline{2})$. Om lag 400 personer lever med sykdommen, med en gjennomsnittlig levetid fra diagnose på to år (3), og ca. $10 \%$ av pasientene lever mer enn ti år. Den klart vanligste dødsårsaken er respirasjonssvikt. Selv om amyotrofisk lateral sklerose regnes som en motorisk sykdom, er det velkjent at om lag halvparten av pasientene får en lett kognitiv svekkelse av frontotemporal type, og opptil $25 \%$ blir demente. Det vanligste er at det oppstår en svikt i innsikt knyttet til sykdommen eller språkforstyrrelse (4).

Behandlingen av pasienter med amyotrofisk lateral sklerose bør skje i tett samarbeid mellom nevrologer og lungeleger. Ved utvikling av begynnende respirasjonssvekkelse vil pasienter i dag tilbys ikke-invasiv ventilasjonsstøtte (hjemmerespirator med masketilslutning). Symptomer på hypoventilasjon kan være hodepine og redusert allmenntilstand eller tretthet på dagtid. Disse symptomene bedres ved behandling med ikke-invasiv ventilasjonsstøtte. Slik bruk er også vist å kunne gi noe forlenget overlevelse (5, 6), men kan være teknisk vanskelig dersom pasientene har bulbære symptomer som svekkelse i tunge og svelg. Hos disse pasientene og hos pasienter som konkret ønsker livsforlengende behandling, kan det være aktuelt med respirator via trakeostomi. Slik behandling reiser betydelige etiske spørsmål både for pasient, familie og helsepersonell (7.).

\section{Hva sier lovverket?}

Pasient- og brukerrettighetsloven skal sikre pasienter lik tilgang og kvalitet på nødvendige helsetjenester fra kommune og spesialisthelsetjeneste. I 2012 ble Nasjonal veileder for langtids mekanisk ventilasjon publisert (ㅁ). Det fremgår i veilederen at det er spesialisthelsetjenesten som avgjør hvorvidt mekanisk ventilasjonsstøtte skal igangsettes hos den enkelte pasient, men at pasient og pårørende skal ha mulighet til å medvirke til beslutningen.

Pasienten kan således ikke kreve livsforlengende behandling med respirator via trakeostomi. Den endelige beslutningen må tas av ansvarlig spesialist, vanligvis etter vurdering og drøfting i det tverrfaglige ALS-teamet ramme 1). Legen kan imidlertid bli satt 
under stort press fra pasient og familie. Det finnes flere eksempler på at pasienter har benyttet pressen for å få endret beslutninger knyttet til livsforlengende behandling ((9.). Det finnes ingen etablert juridisk praksis.

\section{Ramme 1 Før livsforlengende langtids mekanisk ventilasjonsbehandling ved amyotrofisk lateral sklerose gis, anbefaler forfatterne at følgende er vurdert/drøftet:}

Pasienten er vurdert som kognitivt intakt av erfarne klinikere

Pasienten kan bruke adekvate kommunikasjonshjelpemidler

Ikke-invasivt respirasjonshjelpemiddel (BiPAP/hjemmerespirator tilsluttet maske) dekker ikke ventilasjonsbehovet

Både pasient og pårørende er informert om forventet sykdomsutvikling og utfordringer ved behandling via trakeostomi

Pasienten har et konsistent ønske om at behandlingen skal etableres. Informasjon om behandlingen skal være gitt flere ganger

Pasienten skal være informert om palliative alternativer

Pasientens motivasjon for å velge trakeostomi skal være klarlagt

Det skal ha vært vurdert hvorvidt det er mulig å etablere ressurser som kan ivareta pasientens omsorgsbehov ved gjennomføring av invasiv behandling

Kriterier og vilkår for å avslutte respiratorbehandlingen må være diskutert med pasient og pårørende

\section{Hvor vanlig er behandlingen?}

Bruk av ventilasjonsst $\varnothing$ tte via trakeostomi ved amyotrofisk lateral sklerose varierer betydelig. I England er dette svært sjelden benyttet. Vanligst er det i Japan, hvor opptil $45 \%$ av pasientene mottar livsforlengende behandling. I Europa og i USA varierer bruken fra $5 \%$ til $10 \%(\underline{6}, \underline{10})$.

I Norge ble det i perioden 2002-07 gitt ventilasjonsstøtte via trakeostomi til 6,7\% av menn og 3,8 \% av kvinner med amyotrofisk lateral sklerose (11). Data fra Nasjonalt register for langtids mekanisk ventilasjon (LTMV-registeret) viser at det i 2017 var 113 pasienter i aktiv behandling med langtids mekanisk ventilasjon, 32 (28\%) med trakeostomi og 81 (72\%) med masketilslutning. I perioden 2015-20 var det 256 ALS-pasienter som startet opp langtids mekanisk ventilasjon i Norge (모).

\section{Etiske problemstillinger}

Både ikke-invasiv og invasiv respiratorbehandling gjennomføres i utgangspunktet for å bedre pasientens livskvalitet, eventuelt også forlenge levetiden. Symptomer som utmattelse, hodepine og kvelningsfornemmelse ved obstruksjoner i luftveiene er symptomer som reduserer livskvaliteten ved avansert sykdom. Ved bruk av respirator via trakeostomi vil pasienter dessuten kunne leve i mange år. En dansk studie viste at trakeostomerte pasienter ble behandlet i 2,8-4,7 år (13). 2-4 års forlenget overlevelse ved bruk av invasiv respiratorbehandling er også publisert $(\underline{14}, \mathbf{1 5})$. En nylig japansk studie viste

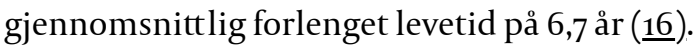


Flere studier viser at pasienter med amyotrofisk lateral sklerose opprettholder god livskvalitet gjennom denne typen avansert behandling, og at pasienter ofte bedømmer egen livskvalitet som høyere enn legen gjør $(\underline{15}, \underline{16}, 177$.$) . Psykologiske, sosiale og$ eksistensielle faktorer betyr mer for egenrapportert livskvalitet ved amyotrofisk lateral sklerose enn fysisk funksjonsnivå (묘). I praksis er det imidlertid ofte svært vanskelig å bedømme livskvalitet hos pasienter som nærmer seg locked-in-syndrom, dvs. å være våken, men uten evne til å kommunisere. Dette gjelder særlig dersom kognisjon og språkfunksjon også er affisert. Det er vanskelig for pasienter å vurdere livskvalitet når alternativet er død (7.). Pasientene kan ha skyldfølelse overfor familiemedlemmer for den situasjonen alle befinner seg i når en pasient behandles med ventilator gjennom trakeostomi.

En utfordring når pasienter med amyotrofisk lateral sklerose behandles med respirator via trakeostomi, er at døden ofte må besluttes (19.). Pasienter må etter vårt syn informeres om dette før behandling tilbys. Pasientene vil ha rett til å avslutte behandlingen når de ønsker, men dette kan naturligvis være en svært vanskelig avgjørelse. En betydelig utfordring for pasient og behandler er redusert kommunikasjonsevne. Normalt vil man ved behandlingsstart lage en avtale med pasienten om å avslutte behandlingen når det ikke lenger er mulig for behandler og pasient å kommunisere. En slik avtale er imidlertid ikke juridisk bindende for pasienten, som vil ha mulighet til å trekke den tilbake i ettertid. Avtalen vil imidlertid bidra til å sikre at pasienten er informert og har reflektert over disse spørsmålene, og vil i ettertid dokumentere pasientens vilje ved behandlingsstart. I sluttfasen vil øyekommunikasjon være vanskelig. Behandler kan være redd for å ikke helt forstå hva pasienten mener. Dette kan føre til overbehandling.

\section{«Negative konsekvenser for familien må vurderes når man skal}

bestemme behandlingen»

I medisinsk etikk er det et viktig prinsipp at man ikke skal skade pasienten. Ved amyotrofisk lateral sklerose er det imidlertid også en problemstilling at man kan skade familien. Respiratorbehandling gitt via trakeostomi påvirker ikke bare pasienten, men også i høy grad familie og helsepersonell. Kulturelle forskjeller er av betydning for om

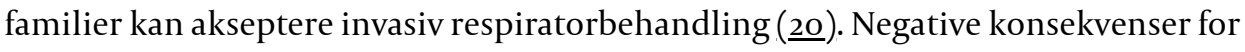
familien må vurderes når man skal bestemme behandlingen. Vi mener at dette må diskuteres med pasienten forut for oppstart av respiratorbehandling via trakeostomi.

Det finnes få gode studier på pårørendebelastning. Pårørende opplever redusert

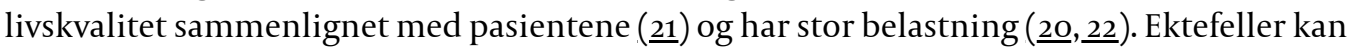
føle seg låst i situasjonen. Skilsmisse eller separasjon kan bli sett på som nådeløst. Pårørende har derfor ikke annet valg enn å følge pasienten. Tidsperspektivet er usikkert. Dette påvirker i betydelig grad pårørendes livskvalitet. I en amerikansk studie var over halvparten av de pårørende deprimerte på det tidspunktet man besluttet slik behandling, men i løpet av behandlingstiden ble antallet som hadde depressive symptomer redusert (23). Pasienten kan ikke alene ha ansvaret for denne type beslutninger. Diskusjon mellom lege, pasient og pårørende er helt nødvendig for å belyse hvordan behandling via trakeostomi vil påvirke pasient og familie.

Et annet viktig prinsipp i all medisinsk behandling er respekt for pasientens autonomi. ALS-pasienter kan oppleve redusert kognitiv funksjon som kan variere fra subtil språkforstyrrelse til reduserte eksekutive funksjoner (24). Vi mener man alltid skal vurdere hvorvidt pasienter forstår hva beslutninger om fremtidig behandling kan bety for familie og andre omsorgspersoner. Dette er spesielt viktig for pasienter med lett frontal svekkelse 
uten klinisk frontotemporal demens. Pasientene vil mangle forståelse for hvordan sykdommen og behandlingen kan påvirke situasjonen for ektefelle og særlig for barn. Man må ta stilling til hvorvidt pasienten har tilstrekkelig innsikt til å forstå konsekvenser av beslutninger. Dersom den kognitive svekkelsen går ut over språkfunksjon, vil det bli svært vanskelig å kommunisere med pasienter som får invasiv respiratorbehandling.

\section{«Det er vanskelig for pasientene 'å velge å dø', men det er også svcert vanskelig 'å velge å leve'»}

Det er vår erfaring at mange pasienter «skyver på beslutningen» om livsforlengende behandling med respirator. De opplever det som en belastning å snakke om det, og de forstår godt at dette er svært vanskelig også for familien. Det er vanskelig for pasientene «å velge å dø», men det er også svært vanskelig «å velge å leve». Man må respektere pasientens $\emptyset$ nske om å unngå denne typen diskusjon, selv om det kan være vanskelig for behandlere av pasienter i avansert stadium at det ikke er tatt noen avgjørelse om livsforlengende behandling. Det er vår oppfatning at ALS-pasienter som ikke ønsker å snakke om livsforlengende behandling, ikke er aktuelle for respiratorbehandling via trakeostomi.

\section{Konklusjon}

Amyotrofisk lateral sklerose er en av få sykdommer hos voksne der det er mulig å forlenge pasientens liv etter at sykdommen har kommet til et endestadium hvor man ikke lenger kan leve uten avansert medisinsk behandling. Behandling med respirator via trakeostomi gjennomføres hos ca. $6 \%$ av norske ALS-pasienter. Beslutning om behandling fattes av lege i samråd med pasient, familie og øvrig medisinsk personell. Det er vår anbefaling at pasienter og pårørende informeres svært grundig. Pasienten må være egnet for behandlingen ut fra ønske og kognitiv funksjon, familie og kommunalt hjelpeapparat må være i stand til å gjennomføre behandlingen og det må foreligge en plan for når behandlingen skal avsluttes.

\section{LITTERATUR}

1. Nakken O, Lindstrøm JC, Tysnes OB et al. Assessing amyotrophic lateral sclerosis prevalence in Norway from 2009 to 2015 from compulsory nationwide health registers. Amyotroph Lateral Scler Frontotemporal Degener 2018; 19:303-10. [PubMed][CrossRef]

2. Nakken O, Lindstrøm JC, Tysnes OB et al. Mortality trends of amyotrophic lateral sclerosis in Norway 1951-2014: an age-period-cohort study. J Neurol 2016; 263: 2378-85. [PubMed][CrossRef]

3. Rooney J, Byrne S, Heverin M et al. A multidisciplinary clinic approach improves survival in ALS: a comparative study of ALS in Ireland and Northern Ireland. J Neurol Neurosurg Psychiatry 2015; 86: 496-501. [PubMed][CrossRef]

4. Woolley SC, Strong MJ. Frontotemporal dysfunction and dementia in amyotrophic lateral sclerosis. Neurol Clin 2015; 33: 787-805. [PubMed][CrossRef]

5. Radunovic A, Annane D, Rafiq MK et al. Mechanical ventilation for amyotrophic lateral sclerosis/motor neuron disease. Cochrane Database Syst Rev 2017; 10: CDoo4427. [PubMed][CrossRef]

6. Spittel S, Maier A, Kettemann D et al. Non-invasive and tracheostomy invasive ventilation in ALS: utilisation and survival rates in a cohort study over 12 years in Germany. Eur J Neurol 2020; 28: 1160-71. [PubMed][CrossRef]

7. Magelssen M, Holmøy T, Horn MA et al. Ethical challenges in tracheostomy-assisted ventilation in amyotrophic lateral sclerosis. J Neurol 2018; 265: 2730-6. [PubMed][CrossRef] 
8. Nasjonal veileder for langtids mekanisk ventillasjon. Kapittel 9.4.1. Oslo: Helsedirektoratet, 2012. https://www.helsedirektoratet.no/veiledere/langtids-mekanisk-ventilasjon-ltmv/Nasjonal-veilederfor-langtids-mekanisk-ventilasjon-ltmv.pdf/_/attachment/inline/coc5fizb-58b9-4cef-8a2c-

4e6afdf26e99:4e60148bd277c5f95bf3b244eaf1bbc764bod6fb/Nasjonal-veileder-for-langtids-mekaniskventilasjon-ltmv.pdf Lest 15.3.2021.

9. Bakke P, Barth-Heyerdahl L. Pål får pustehjelpen Freddy nektes. TV2 5.3.2013.

https://www.tv2.no/a/13641565/ Lest 15.3.2021.

10. Weber C, Fijalkowska B, Ciecwierska K et al. Existential decision-making in a fatal progressive disease: how much do legal and medical frameworks matter? BMC Palliat Care 2017; 16: 80. [PubMed] [CrossRef]

11. Tollefsen E, Midgren B, Bakke P et al. Amyotrophic lateral sclerosis: gender differences in the use of mechanical ventilation. Eur J Neurol 2010; 17: 1352-7. [PubMed][CrossRef]

12. LTMV rapport. Årsrapport for 2019 med plan for forbedringstiltak. Bergen: Nasjonalt register for langtids mekanisk ventilasjon, 2020.

https://www.kvalitetsregistre.no/sites/default/files/17_arsrapport_2019_ltmv.pdf.

13. Dreyer P, Lorenzen CK, Schou L et al. Survival in ALS with home mechanical ventilation noninvasively and invasively: a 15-year cohort study in west Denmark. Amyotroph Lateral Scler Frontotemporal Degener 2014; 15: 62-7. [PubMed][CrossRef]

14. Spataro R, Bono V, Marchese $S$ et al. Tracheostomy mechanical ventilation in patients with amyotrophic lateral sclerosis: clinical features and survival analysis. J Neurol Sci 2012; 323: 66-70. [PubMed][CrossRef]

15. Sanjuán-López P, Valiño-López P, Ricoy-Gabaldón J et al. Amyotrophic lateral sclerosis: impact of pulmonary follow-up and mechanical ventilation on survival. A study of 114 cases. Arch Bronconeumol 2014; 50: 509-13. [PubMed][CrossRef]

16. Hayashi N, Atsuta N, Yokoi D et al. Prognosis of amyotrophic lateral sclerosis patients undergoing tracheostomy invasive ventilation therapy in Japan. J Neurol Neurosurg Psychiatry 2020; 91: 285-90. [PubMed][CrossRef]

17. Vianello A, Arcaro G, Palmieri A et al. Survival and quality of life after tracheostomy for acute respiratory failure in patients with amyotrophic lateral sclerosis. J Crit Care 2011; 26:329.e7-14. [PubMed][CrossRef]

18. Chiò A, Gauthier A, Montuschi A et al. A cross sectional study on determinants of quality of life in ALS. J Neurol Neurosurg Psychiatry 2004; 75: 1597-601. [PubMed][CrossRef]

19. Holmøy T, Aarrestad S, Engstrand P et al. Avslutning av respiratorbehandling ved amyotrofisk lateral sklerose. Tidsskr Nor Legeforen 2009; 129: 628-31. [PubMed][CrossRef]

20. Kaub-Wittemer D, Steinbüchel N, Wasner M et al. Quality of life and psychosocial issues in ventilated patients with amyotrophic lateral sclerosis and their caregivers. J Pain Symptom Manage 2003; 26: 890-6. [PubMed][CrossRef]

21. Christodoulou G, Goetz R, Ogino M et al. Opinions of Japanese and American ALS caregivers regarding tracheostomy with invasive ventilation (TIV). Amyotroph Lateral Scler Frontotemporal Degener 2015; 17: 47-54. [PubMed][CrossRef]

22. Lerum SV, Solbrække KN, Frich JC. Family caregivers' accounts of caring for a family member with motor neurone disease in Norway: a qualitative study. BMC Palliat Care 2016; 15: 22. [PubMed] [CrossRef]

23. Rabkin JG, Albert SM, Rowland LP et al. How common is depression among ALS caregivers? A longitudinal study. Amyotroph Lateral Scler 2009; 10: 448-55. [PubMed][CrossRef]

24. Woolley SC, Rush BK. Considerations for clinical neuropsychological evaluation in amyotrophic lateral sclerosis. Arch Clin Neuropsychol 2017; 32: 906-16. [PubMed][CrossRef]

Publisert: 14. mai 2021. Tidsskr Nor Legeforen. DOI:10.4045/tidsskr.20.1030

Mottatt 16.12.2020, første revisjon innsendt 19.2.2021, godkjent 15.3.2021.

(C) Tidsskrift for Den norske legeforening 2023. Lastet ned fra tidsskriftet.no 26. april 2023. 